\title{
EDUCAÇÃO INTERCULTURAL, MÍDIA E MEDIAÇÕES: APORTES DAS TEORIAS LATINO-AMERICANAS DA COMUNICAÇÃO E CONSUMO CULTURAL
}

\author{
Maria Isabel Orofino
}

O mundo encurta, o tempo se dilui. O ontem vira agora; o amanhã já está feito. Tudo muito rápido. Debater o que se diz, o que se mostra e como se mostra na televisão me parece algo cada vez mais importante. (Paulo Freire: Pedagogia da Indignação, 2000:109)

\section{INTRODUÇÃO}

Se uma pedagogia libertadora advoga que a leitura do mundo antecede e acompanha a leitura da palavra, o que significa então a leitura de um "mundo globalizado" em que os meios de comunicação desempenham um papel fundamental na consolidação de tal processo? Que integrações ele explicita e que exclusões oculta? Que papel as mídias desempenham hoje tanto nos processos de difusão de ideologias quanto na construção de novas redes de solidariedade mundial? Ao colocar estas perguntas quero defender a necessidade de os profissionais do campo da Educação colocarem em pauta as novas reflexões sobre o papel das mídias nas sociedades contemporâneas. Acredito que precisamos ampliar nossas ações a partir das mediações escolares e dos movimentos sociais por meio de novos enfoques pedagógicos que visem um consumo cultural crítico e que possibilitem a criação de estratégias de uso destes meios para fins emancipatórios e libertadores.

Neste sentido, o objetivo deste artigo é discutir alguns aspectos relacionados aos estudos da mídia e da educação intercultural enquanto prática de intervenção educativa que problematize para além da descrição do caráter multicultural das sociedades contemporâneas e identifique aqueles espaços intersticiais, os entrelugares que efetivamente constituem as novas identidades sociais (individuais e coletivas). O artigo advoga a importância de se pensar o espaço ocupado pela mídia na relação com as demais dimensões constitutivas da cultura como etnia, gênero, classe, orientação sexual, geração, dentre outras. Nesta perspectiva, o que prendendo neste texto é dar visibilidade à contribuição das Teorias LatinoAmericanas das Mediações sobretudo a partir dos escritos de Jesús MartínBarbero; uma referência importante para aqueles que buscam uma prática educacional intercultural que esteja atenta ao importante papel que os meios de comunicação desempenham na constituição das dinâmicas culturais contemporâneas. 


\section{EDUCAÇÃO INTERCULTURAL, MÍDIA E MEDIAÇÕES}

Uma relação intercultural pode ser pensada como sendo aquela situação em que pessoas de culturas diferentes interagem ou ainda como uma atividade que requeira tal interação. Segundo Reinaldo Fleuri:

"Para além da oposição reducionista entre o monoculturalismo e o multiculturalismo surge a perspectiva intercultural. Esta emerge no contexto das lutas contra os processos crescentes de exclusão social. Surgem movimentos sociais que reconhecem o sentido e a identidade cultural de cada grupo social. Mas, ao mesmo tempo, valorizam o potencial educativo dos conflitos. E buscam desenvolver a interação e reciprocidade entre grupos diferentes como fator de crescimento cultural e de enriquecimento mútuo. Assim, em nível das práticas educacionais, a perspectiva intercultural propõe novas estratégias de relação entre sujeitos e entre grupos diferentes. Busca promover a construção de identidades sociais e o reconhecimento das diferenças culturais. Mas, ao mesmo tempo, procura sustentar a relação crítica e solidária entre elas" (Fleuri, 2001:113).

Neste sentido, se a educação intercultural enfatiza a relação intencional entre sujeitos de diferentes culturas então estas precisam ser pensadas também a partir de uma hibridação que se constitui nas tensões entre comunidades locais e os sentidos circulantes que são difundidos por práticas midiáticas. Cada vez mais, sujeitos e grupos sociais dispersos no espaço constroem novas comunidades de apropriação e de referência a partir dos conteúdos veiculado pelas mídias. Há que se acrescentar este dado à perspectiva de educação intercultural no sentido de que a pluralidade e hibridez não são apenas aquele traço do encontro e confronto entre diferentes etnias. Mas ocorrem sobretudo a partir da articulação entre diferentes modos de representação do mundo. Neste movimento aquela cultura midiática dominante que atua em nível planetário e globalizado colide com os modos de apropriação construídos em diferentes contextos sócio-históricos.

Neste sentido, se quisermos avançar no debate da prática educativa intercultural, precisamos destacar a importância que as indústrias da mídia e os múltiplos e contraditórios conteúdos por elas veiculados desempenham nos processos de constituição de identidades individuais e coletivas. E precisa-se não apenas considerar o papel das indústrias e seus conteúdos mas sobretudo e fundamentalmente os cenários da recepção e do consumo como o locus de ações educativas em que os sentidos dominantes das mensagens veiculadas pelos sistemas mercantis de produção da cultura podem efetivamente ser subvertidos e ressignificados. Daí a importância daquelas teorias da comunicação que possam trazer aportes para a prática educacional crítica e libertadora.

\section{ESTUDOS DA MÍDIA E AS TEORIAS DAS MEDIAÇÕES LATINO- AMERICANAS}


Com respeito ao debate sobre a problemática da mídia e cultura, a América Latina se caracteriza hoje como um espaço de grande criatividade intelectual e esta contribuição teórico-metodológica merece ser destacada. Neste sentido há uma contribuição significativa que os Estudos Culturais da Mídia podem trazer para o debate sobre a Educação. Com o objetivo de apresentar que contribuições substantivas são estas, acredito que convenha resgatar a trajetória de produção deste corpus teórico-metodológico em particular.

As teorias das mediações ganharam visibilidade na América Latina com o desenvolvimento dos estudos qualitativos de recepção[1], especialmente a partir dos anos 80. Mas, a preocupação com a atividade dos receptores já era tema de debate entre estudiosos críticos na esfera internacional de pesquisa em comunicação social. Os estudos críticos de audiência, como também são denominadas estas iniciativas de pesquisa, ficaram conhecidos com o trabalho do

Centre for Contemporary Cultural Studies da Universidade de Birmingham[2], tendo como nomes centrais os autores Richard Hoggart e Stuart Hall, fundamentados principalmente no trabalho de E. P. Thompson e Raymond Williams. Dentre os autores vinculados ao CCCS de Birgmingham, a etnografia de audiência realizada por David Morley e Charlotte Brunsdon sobre a recepção do programa Nationwide registrou o marco inicial desta tendência de pesquisa. Há entretanto outros marcos referenciais dentro deste campo de investigação que não estiveram necessariamente ligadas ao CCCS de Birmingham, como é o caso do trabalho de James Lull[3] sobre o consumo de TV com famílias na China, Ien Ang, Janice Radway, por exemplo. Não é objetivo deste trabalho traçar um histórico das relações entre os estudos de recepção latino- americanos e suas tendências internacionais ${ }^{[4]}$.

O que desejo destacar aqui é que há portanto um determinado momento na história das teorias da comunicação em que tornou-se fundamental para a pesquisa crítica investigar os modos através dos quais, em seu cotidiano, cidadãos comuns efetivamente usam os meios de comunicação e produzem sentido a partir de sua vasta discursividade. Buscou-se problematizar o sentido de atividade presente nos atos de consumo. A pesquisa crítica deslocou o foco das análises estruturais e econômicas da produção, suas determinações e o conteúdo ideológico das mensagens para, pela primeira vez, se debruçar sobre a recepção[5], os usos e apropriações que os cidadãos fazem da televisão (e de outros meios) na esfera da vida cotidiana.

Isto se caracterizou como um primeiro deslocamento de eixo e portanto trouxe uma nova perspectiva para os estudos críticos da comunicação. Para compreender melhor este deslocamento no âmbito das teorias gerais da comunicação e também o importante papel que as teorias das mediações desempenham hoje na pesquisa de comunicação crítica latino-americana é necessário voltar a nossa atenção para a história destas teorias em nosso próprio continente. Lançar um olhar ao passado recente permite que a história política nos mostre de que modo alguns caminhos foram trilhados e possibilitaram a emergência deste conjunto teórico particular como "nova" perspectiva para o 
estudo dos fenômenos ligados à comunicação social.

Não é possível afirmar que as teorias das mediações têm na América Latina o seu locus de criação[6]. Porém, existe uma trajetória de consistência e detalhamento teórico-metodológico - especialmente na relação entre os meios de comunicação, as audiências, o consumo cultural e as mediações - já alcançados pelos autores latino-americanos que é possível afirmar que há, não exatamente uma autoria, mas sim uma autoridade na proposta por eles desenvolvida. Portanto, no que se refere a este campo de estudos, a América Latina se caracteriza hoje como um laboratório de criatividade teórica. Esta autoridade de que falei acima, de certa forma, confere uma identidade à nossa produção, a qual pode ser mais bem compreendida se analisarmos as conexões entre a recente história social e política e a produção de conhecimento em nosso continente.

Como destaca Guillermo Orozco (1993b:22), as abordagens teóricometodológicas de estudos da recepção que foram desenvolvidas na América Latina a partir da penetração do conceito de hegemonia de Gramsci e da visão cultural dos meios de comunicação patrocinada pelos estudos culturais do Centre for Contemporary Cultural Studies de Birmingham, somam mais de sete modelos distintos. Dentre eles destacam-se as correntes conhecidas como: consumo cultural, desenvolvida por Nestór García Canclini; frentes culturais, coordenada por Jorge González no Programa de Estudios sobre las Culturas Contemporâneas (Colima/México); recepção ativa, elaborada por Fuenzallida e Hermosilla pertencentes ao Centro de Indagación y Expresión Cultural y Artística (CENECA/Chile); o enfoque uso social do meios, concebido por Jesús MartínBarbero (Bogotá, Colômbia); e enfoque integral da audiência (proposta que é de sua autoria).

\section{TEORIA, IDENTIDADE E LUTA}

É difícil definir alguma identidade latino-americana. O fato de o Brasil ser um dos poucos países no continente a não ter sido colonizado pelos espanhóis e não compartilhar do mesmo idioma já é um dado básico que não nos permitiria qualquer tentativa de totalização em torno do conceito de identidade. Nosso continente é palco também de tamanha diversidade étnica em termos de diferentes grupos indígenas que co-existem com todos os diferentes grupos de imigrantes europeus chegados no século 19 que, como destaca Néstor García Canclini (1998), somos um espaço social em que se gesta uma cultura híbrida. Esta tradução, da realidade cultural em hibridez, me parece oferecer um excelente conceito para se pensar qualquer identidade para a América Latina. Se é que existe alguma, ela precisa ser pensada em termos de dissonância e descontinuidade.

Mas, por outro lado, os povos latino-americanos compartilham alguma identidade se pensarmos nos processos de luta social que marcam suas trajetórias sócioculturais. Lutas que foram, em vários sentidos (ainda que muito diferentes em seus contextos reais de ocorrência) vividas como conseqüência dos processos de 
colonização desde o século 16. Também, no passado recente (especialmente a partir década de 60), com as tentativas de construção de democracias socialistas que foram duramente massacradas pela Guerra Fria através da imposição das ditaduras militares apoiadas pelos Estados Unidos com o uso do autoritarismo e da violência. Na esteira desta trajetória, preciso destacar também os modos mais recentes de respostas populares e movimentos sociais que caracterizam ações de resistência aos múltiplos processos de exclusão social desencadeados pelo modelo neoliberal de gestão da economia em todo o nosso continente.

Como articular possíveis conexões entre alguns eventos políticos mais recentes (aqui me refiro à experiência política das ditaduras militares e aos modos de repressão subseqüentes às suas implantações) e a produção de teoria social? Em especial as teorias críticas da comunicação que foram desenvolvidas nestes países, sobretudo na Colômbia, Argentina, Chile e Brasil? Para responder a estas perguntas recorro a um breve resgate da história política em nosso cenário social. Afinal, toda reflexão crítica precisa estabelecer laços entre produção de conhecimento e da cultura e o contexto sócio-histórico no qual este é produzido.

\section{A TEORIA CRÍTICA SOB O VENTO FORTE DAS DITADURAS E A EMERGÊNCIA DA TEORIA DA ABERTURA E DA GERAÇÃO PÓS-GOLPE.}

A violenta atmosfera que cobriu a grande maioria dos países latino-americanos no início dos anos 60 e mais intensamente nos anos 70, forçou ao silêncio grande parte da produção cultural e acadêmica que vinha florescendo naquele período. Há uma frase popular que diz: "nunca havíamos sido tão inteligentes como nos anos que antecederam ao golpe". No Brasil, por exemplo, as cenas política e intelectual se caracterizavam pela efervescência de movimentos e formações em diferentes campos da produção cultural que podem ser facilmente identificados ao lembrarmos do trabalho teórico de Paulo Freire com a Pedagogia do Oprimido; das tendências progressistas da igreja através da Teologia da Libertação, da reflexão sociológica com as Teorias da Dependência, da música com a Tropicália e a Bossa Nova, do Teatro do Oprimido e do Cinema Novo, etc., etc.. Não apenas em nosso país, mas em vários locais do continente, uma verdadeira antropofagia intelectual explodia em cores, ritmos e tons, deixando marcas da imaginação criativa latino-americana nos registros históricos.

Neste mesmo período, com o desenvolvimento de novas tecnologias de difusão da informação, ocorreu também uma ampliação significativa do mercado cultural através do crescimento e expansão das indústrias midiáticas, o que ajudou a desencadear o interesse acadêmico em pesquisas de comunicação social.

No início dos anos 60, a pesquisa de comunicação estava organizada em duas vertentes básicas: (1) aquela de caráter administrativo e desenvolvimentista orientado pela perspectiva funcionalista, e (2) a pesquisa crítica com reflexões sobre o poder dos meios de comunicação na difusão de ideologias de mercado (Lopes, 1996). A implantação do regime autoritário no Brasil em 31 de março de 1964 e em vários países da América Latina nos anos subseqüentes - "em 1976 Argentina, Bolívia, Brasil, Chile, Equador, Paraguai, Peru, Uruguai e toda a América Central (com exceção da Costa Rica) estavam sob ditaduras" (Fox, 
1997:186) - trouxe perseguição, prisão e exílio de intelectuais críticos e a conseqüente tentativa de silenciar suas produções.

Particularmente, no campo da teoria da comunicação, as tendências críticas tomavam como referência abordagens do estruturalismo marxista (Luis Althusser) e da Escola de Frankfurt. Em linhas gerais, denunciava-se a cooptação política dos meios de comunicação com as forças hegemônicas do modelo capitalista e do imperialismo cultural norte-americanos. A comunicação social passou a ser problematizada via análise de corporações transnacionais, suas imposições culturais, a violência simbólica e a imposição de ideologias sobre as culturas locais. No âmbito das análises das mensagens, a ênfase recaia sobre a identificação das ideologias subjacentes aos discursos midiáticos. Aqui as referências teóricas se originavam na semiologia estruturalista (Saussure e por extensão Roland Barthes) e nas análises de discurso da linha francesa (Emile Benveniste e Michel Pecheux). Em grande medida, estes estudos brasileiros buscavam denunciar as estratégias de "dominação" realizadas pelos meios de comunicação.

Cabe destacar aqui que as perspectivas funcionalistas, sobretudo com influência da sociologia norte-americana (Talcott Parsons e Robert Merton) eram dominantes na pesquisa de comunicação. Esta orientação epistemológica se manteve hegemônica até o final dos anos 80 , período em que a abertura democrática tornou-se viável.

A partir dos anos 80, um intenso processo de redemocratização se estende por quase toda a América Latina. Apesar de todas as estratégias de coerção realizadas pelos governos militares, as vozes dissidentes na academia não silenciaram. Assim como não silenciaram nas outras esferas da produção cultural.

No Brasil, em várias cidades, a população veio às ruas reivindicar abertura política e eleições diretas para a presidência da República. Na Argentina, as Mães da Praça de Maio pedem o retorno de seus filhos e filhas desaparecidos. A ação de novos movimentos sociais ganha força e visibilidade, sobretudo o movimento ecológico, feminista e de construção de identidades étnicas. Os estudos críticos em comunicação dialogam com esta efervescência sócio-cultural e política redirecionando o foco das análises para os movimentos populares e para os mecanismos de resistência que as culturas locais produzem na rearticulação da estruturas de dominação. Sobre este período Lopes (1993) explica que:

"É no início dos anos 80 que se dá a emergência dos estudos de recepção na América Latina, no âmago de um forte movimento teórico-crítico que procurava fazer uma reflexão alternativa sobre a comunicação e a cultura de massas através da perspectiva gramsciana; reflexão alternativa às análises semióticas e frankfurtianas predominantes até então. É sobretudo dentro da temática das culturas populares que uma teoria complexa e multifacetada da recepção começou a se desenvolver, tendo como eixos básicos de reflexão o deslocamento dos meios às mediações (Martín-Barbero) e os processos de hibridização 
cultural (Garcia Canclini). (Lopes,1993: 78).

De acordo com Mattelart e Mattelart (1995), em sua breve história das teorias da comunicação, se os anos 70 foram marcados pelos desenvolvimento de estudos críticos que enfatizavam processos de desterritorialização (com ênfase para as estratégias dos macro-sujeitos, isto é, estados-nacionais, organismos internacionais e corporações multinacionais), os anos 80 em contrapartida, passam a enfatizar os processos de territorialização. Isto é, a ênfase recai sobre processos de negociações, resistências e mediações entre fatores externos e realidades particulares. Ao discutir a produção de teoria crítica da comunicação em nível internacional, os autores identificam na América Latina o deslocamento a que me refiro. Eles explicam:

"O fato de a concepção essencialista do universal e do logos ocidental ter sido posta em questão atrai outros atores para a produção de conceitos e teorias. São disso testemunho os estudos antropológicos sobre as culturas transnacionais e sobre as identidades confrontadas com os fluxos da modernidade global, que tanto na Ásia como na América Latina, se questionam sobre os processos complexos de apropriação e reapropriação, de resistência e de mimetismo. Novos conceitos exprimem esse desejo de uma melhor abordagem dessas articulações finas: crioulização, mestiçagem, hibridação ou modernidade alternativa [Barbero, 1987; Ortiz, 1988; Garcia Canclini, 1990; Appadurai, 1990]. O mesmo desejo inspira as investigações sobre a genealogia dos gêneros das indústrias audiovisuais locais, que suscitam em territórios específicos a adesão do grande público" (1995: 143).

Armand e Michelle Mattelart referem-se, portanto, ao surgimento do interesse pelo desenvolvimento dos estudos de recepção. Estudos que se caracterizaram pelas estratégias de metodologia qualitativa e etnográfica e cujo foco era compreender os modos através dos quais as audiências se apropriam das mensagens difundidas pelos meios de comunicação.

\section{CONCLUSÕES}

Para concluir, eu gostaria de sugerir que uma das principais contribuições que este debate pode trazer para o campo da Educação é uma problematização da presença das mídias nos contextos sócio-históricos contemporâneos que não incorra em uma visão maniqueísta, que situe os meios de comunicação apenas como agências vinculadas aos interesses perversos do mercado. O que se busca aqui é a compreensão de uma dinâmica complexa, contraditória porque histórica. A constituição das audiências não é um fator determinado somente pelo mercado. Há uma dialética própria entre, por um lado, os fatores que definem a produção e, por outro lado, as demandas culturais e históricas, as memórias sociais e os gostos populares que por sua vez interpelam os meios massivos de comunicação. Isto pode ser um caminho para problematizarmos a ação da mídia para além das concepções de manipulação e alienação, integrando uma articulação que vem das demandas sociais e que pode explicar o alto grau de 
consumo dos mídias pelas populações. A formação de um público para uma determinada obra midiática se faz, segundo Martín-Barbero, pela articulação do contexto da cotidianidade com competências culturais e temporalidades sociais. Compete a nós, educadores, uma apropriação destas referências que têm origem nas teorias da comunicação social para que possamos atualizar a crítica aos meios de comunicação e não abrir mão dela. Com uma renovação de nossas referências teórico-metodológicas, poderemos avançar mais substantivamente no enfrentamento

"do extraordinário poder da mídia, da linguagem da televisão, de sua sintaxe que reduz a um mesmo plano o passado e o presente e sugere que o que ainda não há já está feito" (Paulo Freire, 2000:109).

\section{BIBLIOGRAFIA}

FLEURI, Reinaldo Matias, 2001. Desafios à Educação Intercultural no Brasil. Revista PerCursos. V.2.. No. 2, P.109/128. Núcleo de Estudos em Políticas Públicas. Udesc.

FREIRE, Paulo, 1993: A pedagogia da esperança: um reencontro com a pedagogia do oprimido. São Paulo. Paz e Terra.

FREIRE, Paulo, 2000. Pedagogia da Indignação. São Paulo. Unesp. GARCÍA CANCLINI, Nestor, 1995: Consumidores e Cidadãos: Conflitos Multiculturais da Globalização. Rio de Janeiro. Editora da UFRJ. GARCÍA CANCLINI, Néstor García (et al.), 1998a: Mapas Nocturnos: Diálogos com la obra de Jesús Martín-Barbero. Bogotá. Siglo Del Hombre. GARCÍA CANCLINI, Nestor, 1998: Culturas Híbridas. São Paulo. Edusp. MARTÍN-BARBERO, Jesús, 1989: Procesos de Comunicación y matrices de cultura: itinerário para salir de la razon dualista. México.Ediciones $G$ Gili. MARTíN-BARBERO, Jesús, 1990: De los médios a las practicas. In OROZCO, Guillermo. La Comunicacion desde las practicas sociales: reflexiones em torno a su investigacion. Santa Fé. Universidad Iberoamericana.

MARTÍN-BARBERO, Jesús, 1997 (1987): Dos meios às mediações: comunicação, cultura e hegemonia. Rio de Janeiro: Editora UFRJ.

MARTÍN-BARBERO, Jesús e REY, Germán, 1999: Los ejercicicos del ver: hegemonia audiovisual e ficción televisiva. Barcelona. Editorial Gedisa.

\footnotetext{
[1] Os Estudos de Recepção caracterizam-se como uma área na pesquisa internacional de comunicação e possuem um longa trajetória histórica, ainda que esta designação seja um pouco nebulosa. Em termos gerais, trata-se da problemática de pesquisa que tem na atividade das audiências e suas relações como os meios de comunicação o seu foco principal. Entretanto, nem todas as suas vertentes partem dos pressupostos de uma teoria crítica. Segundo Lopes $(1995,1999)$ e Orozco Gomes (1996) estas pesquisas tem o interesse em estudar o nexo entre os meios de comunicação e as audiências e em sua trajetória de desenvolvimento se consolidaram em diferentes correntes: na vertente funcionalista situam-se: pesquisa dos efeitos, pesquisa dos usos e gratificações. Na perspectiva crítica e hermenêutica: estudos de crítica literária, estudos culturais e estudos de recepção.

[2] Cf. Hoggart, R. 1973: As Utilizações da Cultura. Lisboa, Presença; Hall, S. Encoding/deconding in television discourse, in Hall, S et al., (eds) 1981. Culture, Media, Language, London. Hutchinson; Morley, D. e Brunsdon, C 1978: Everyday television: Nationwide.London. British Film Institute.
} 
[3] Cf. Lull, J. 1988: World families watch television, Newburry Park and London. Sage; Radway, J. 1984: Reading the romance, Chapel Hill. University of North Carolina Press; Ang, I. 1985: Watching "Dallas”, London. Methuen.

[4] Cf. Escosteguy, Ana Carolina. Cartografias dos Estudos Culturais: Stuart Hall, Jesús Martín-Barbero e Nestor García Canclini. Tese de Doutorado apresentada junto ao Departamento de Ciências da Comunicação, Escola de Comunicações e Artes. Universidade de São Paulo, 2000.

[5] O "pela primeira vez” cabe pois ao analisar a história das teorias da comunicação pude verificar que as audiências já tinham sido enfocadas pelas vertentes funcionalistas da comunicação social através da teoria dos efeitos e dos usos e gratificações. O consumo cultural e a atividade dos leitores/receptores foi pela primeira vez problematizada pela teoria crítica via crítica literária e os estudos culturais da Escola de Birmingham que influenciaram substantivamente os estudos de recepção latino-americanos e consequentemente as teorias das mediações em nosso continente.

[6] Teorias das Mediações referem-se a um amplo conjunto de escritos acadêmicos que não diz respeito à ação da mídia em particular, mas sim à vasta problemática da ação reflexiva dos sujeitos sociais na elaboração e reelaboração das formas simbólicas. Mediação é um conceito fundamentalmente crítico e tem na dialética o seu ponto de origem, sobretudo no que se refere à questão da consciência humana frente às possibilidades de se efetivar mudanças sociais no espectro histórico. Trata-se de uma problemática conceitual que foi amplamente discutida por todo o conjunto das teorias marxistas da arte e posteriormente pela sociologia crítica da cultura. Sobre as nuances e variações do conceito de mediação ver o Capítulo 2. 